\title{
Influence of the electrical parameters on the fabrication of copper nanowires into anodic alumina templates
}

\author{
Rosalinda Inguanta, Salvatore Piazza*, Carmelo Sunseri \\ Dipartimento di Ingegneria Chimica dei Processi e dei Materiali, Università di Palermo, Viale delle Scienze, 90128 Palermo, Italy
}

\section{A R T I C L E I N F O}

\section{Article history:}

Received 15 April 2009

Accepted 12 June 2009

Available online 21 June 2009

\section{Keywords:}

Copper nanowires

Anodic alumina membranes

Electrodeposition

Self-standing structures

\begin{abstract}
A B S T R A C T
Metallic copper nanowires have been grown into the pores of alumina membranes by electrodeposition from an aqueous solution containing $\mathrm{CuSO}_{4}$ and $\mathrm{H}_{3} \mathrm{BO}_{3}$ at $\mathrm{pH}$ 3. In order to study the influence of the electrical parameters on growth and structure of nanowires, different deposition potentials (both in the region where hydrogen evolution reaction is allowed or not) and voltage perturbation modes (constant potential or unipolar pulsed depositions) were applied. In all cases, pure polycrystalline $\mathrm{Cu}$ nanowires were fabricated into template pores, having lengths increasing with the total deposition time. These nanowires were self-standing, because they retain their vertical orientation and parallel geometry even after total template dissolution.

However, the electrical parameters influence the growth rate, length uniformity and crystal size of the nanowires. Continuous electrodeposition resulted in higher growth rates but less uniform lengths of nanowires grown inside different membrane pores, whilst a square pulse deposition produced a slower growth but quite uniform lengths. Also the grain size, of the order of $50 \mathrm{~nm}$, was slightly influenced by the potential perturbation mode.
\end{abstract}

(c) 2009 Elsevier B.V. All rights reserved.

\section{Introduction}

Building controlled nanostructures is very important for the electronic and the electro-mechanic industry in order to fabricate efficient devices to a smaller scale, which present higher performances [1]. Among numerous nanostructured materials, several works have been dedicated to the fabrication of $\mathrm{Cu}$ nanowires (NWs) [2-7], because of their potential application in several devices such as in wire-grid polarizers [8], electrostatically dissipative devices [9], and current collectors for Li-ion batteries [10]. For this last application, Taberna et al. [11] have shown that it is possible to achieve an improvement by a factor of six in power density over planar electrodes whilst maintaining the same total discharge time using electrodes composed of $\mathrm{Cu}$ nanorods covered by $\mathrm{Fe}_{3} \mathrm{O}_{4}$. Recently, it was demonstrated that Y-branched $\mathrm{Cu}$ NWs can be used as near-infrared micropolarizers; this could have a promising future in the field of photoelectricity integration [12].

Besides, substitution of aluminium with copper for interconnections in integrated circuits and in high-performance multichip modules constitutes a great improvement in the field of electronics $[13,14]$. This has been possible, thank to a better control in the electrodeposition process of metallic $\mathrm{Cu}$; with this aim, optimiza-

\footnotetext{
* Corresponding author. Tel.: +39 0916567230.

E-mail address: piazza@dicpm.unipa.it (S. Piazza).
}

tion of bath composition was investigated, in order both to increase its throwing power and to obtain very uniform thickness of the metallic deposit $[15,16]$. The effect of various additives (such as polyethylene glycol) on the morphological aspects of nanostructures and on the growth kinetics was investigated and it was showed that growth of $\mathrm{Cu}$ wires or nanotubes is significantly influenced by their action [17].

In previous works $[18,19]$, we presented a novel procedure to obtain pure polycrystalline $\mathrm{Cu}$ NWs using commercial anodic alumina membranes (AAM) as templates: a displacement reaction into membrane pores was caused by a galvanic contact with a less noble metal ( $\mathrm{Al}$ ). Using this procedure, all AAM pores were progressively filled by $\mathrm{Cu}$ NWs in an economic way. However, pore filling was quite slow: 3 days of immersion were needed in order to obtain a NWs length of $44 \mu \mathrm{m}$. An alternative technique for the fabrication of nanostructures is electrodeposition [1-6,20,21], which allows a better process control through the electrode potential, in comparison to others fabrication methods [22-24].

Despite numerous studies on the electrochemical deposition of metal NWs, the literature data on the influence of the electrodeposition conditions on the final deposit are rather contradictory. In the case of $\mathrm{Ni}$ deposition, an influence of the potential perturbation mode was found upon uniformity of template pore filling by metal [25]; in particular, these authors claim nonuniform length of metallic NWs under a constant deposition potential, owing to a progressive depletion of metal ions into the 
pores. Moreover, we found that morphology of Ni nanostructures changed depending on the kind of applied pulsed potential waveform [26]. Contrasting conclusions were reached in [27], where a scarce influence of potential waveform was observed upon length uniformity of electrodeposited copper NWs. For these authors, a continuous deposition produces the best pore filling but it damages the template.

The influence of electrolyte and electrodeposition time on the uniformity of $\mathrm{Cu}$ NWs was studied by Chen et al. [10]. According to these authors, free-standing $\mathrm{Cu}$ NWs (aspect ratio 17-20) can be obtained in alkaline electrolyte, whilst NWs electrodeposited in very acid electrolyte showed the worst uniformity. Liu et al. [28], found that both morphology and crystalline structure of $\mathrm{Cu}$ NWs were influenced by the deposition potential. Gao et al. investigated the fabrication of $\mathrm{Cu}$ NWs from an almost neutral copper sulphate-boric acid aqueous solution [29], only under continuous deposition. They claimed that low cathodic overpotentials are necessary in order to obtain monocrystalline $\mathrm{Cu}$ NWs, growing along the (1 111 ) plane, and to avoid copper oxide formation during continuous deposition. Different results were obtained by Thongmee et al. [6]: they showed that singlecrystalline $\mathrm{Cu}$ NWs could be produced by potentiostatic electrodeposition at relatively high deposition potential $(2.0 \mathrm{~V}(\mathrm{SCE}))$, whilst potentials lower or higher than $2 \mathrm{~V}(\mathrm{SCE})$ resulted in polycrystalline NWs. Maurer et al. [30] observed a preferential orientation along the (2 20 ) plane for fcc gold and copper NWs deposited under direct current, and a growth along the $\left(\begin{array}{lll}2 & 0 & 0\end{array}\right)$ plane under alternating current deposition. According to these authors, this behaviour is due to the tendency of minimization of surface energy during the electrodeposition process: (2 20$)$ and $(200)$ correspond to the lowest energy configuration for NWs obtained by direct and alternating current deposition, respectively. The influence of temperature on the crystallographic structure of copper NWs electrodeposited in polycarbonate templates at low overvoltages was studied in [31]: at room temperature fine-grained polycrystalline NWs were deposited, with increasing temperature the grain size gradually enlarged, until single crystals were obtained as temperature of the electrochemical bath was maintained at $60{ }^{\circ} \mathrm{C}$. In the last case, some wires show a twin structure, resulting, according to the authors, from either the growth process or a plastic deformation.

This overview of the literature data shows that results related to the fabbrication of $\mathrm{Cu}$ NWs by template electrosynthesis are very different, and in some cases, contrasting. In order to clarify some of these aspects, we have undertaken a systematic investigation upon the effect of potential value and perturbation mode on growth and structure of copper NWs from a copper sulphate-boric acid aqueous solution. In particular, we will show the influence of selected deposition conditions on both growth rate and uniformity of NWs length. For this aim, we have investigated the electrodeposition under continuous and unipolar pulsed potential, in order to establish the electrochemical conditions leading to the formation of uniform arrays of copper NWs. This issue is of relevant importance, because a uniform length of nanowires is a fundamental requirement for their application.

We have chosen the AAM as template because, as shown in our previous works, by electrochemical deposition into this template it is possible to fabricate nanowires or nanotubes of metals, oxides and alloys, like $\mathrm{Ni}$ [26,32], $\mathrm{Cu}_{2} \mathrm{O}$ [33,34], $\mathrm{CeO}_{2}$ [35], $\mathrm{PbO}_{2}$ [36], and CoSn [37]. Moreover, using AAM, regular arrays of cylindrical nanostructures are fabricated, in which every single wire has identical morphology, unlike nanostructures obtained in polycarbonate membranes, whose pores show a non-constant crosssection $[31,38,39]$.

\section{Experimental}

Metallic $\mathrm{Cu}$ NWs were grown by template electrodeposition into commercial AAM templates (Whatman, Anodisc 47) having a nominal thickness of $55 \mu \mathrm{m}$, an average pore diameter of about $210 \mathrm{~nm}$ and a surface pore density of the order of $10^{13}$ pores $/ \mathrm{m}^{2}$. Before electrodeposition, one membrane surface was sputtered with a gold layer, to provide the initial electrode surface for metal copper nucleation; then it was mounted onto an aluminium stub through a conductive paste ensuring the back electrical contact, and insulated laterally with a lacquer.

Electrodeposition bath was prepared dissolving $0.2 \mathrm{M}$ of $\mathrm{CuSO}_{4} \cdot 5 \mathrm{H}_{2} \mathrm{O}$ and $0.1 \mathrm{M}$ of $\mathrm{H}_{3} \mathrm{BO}_{3}$ in distilled water; $\mathrm{pH}$ of the solution was adjusted to 3 adding $\mathrm{H}_{2} \mathrm{SO}_{4}$. Before electrodeposition, sample was immersed into the deposition bath for several hours, to let membrane pores be filled by the electrolyte. Electrodepositions were performed at room temperature, in an aerated three electrode cell, having a graphite counter electrode and a standard calomel reference electrode $\left(\mathrm{SCE}, E^{\circ}=0.24\right.$ $\mathrm{V}(\mathrm{SHE})$ ). Electrodeposition potentials were $-0.3,-0.45$ and $-0.6 \mathrm{~V}(\mathrm{SCE})$, well negative with respect to the equilibrium potential of the $\mathrm{Cu}^{2+} / \mathrm{Cu}$ reaction (about $0.07 \mathrm{~V}(\mathrm{SCE})$, at the given $\mathrm{Cu}^{2+}$ concentration); they were chosen considering the concurrent cathodic reaction of $\mathrm{H}_{2}$ evolution $\left(E_{\mathrm{eq}}=-0.47 \mathrm{~V}(\mathrm{SCE})\right.$, at $\mathrm{pH} 3$ ), in order to realize copper electrodeposition under three different situations: absence of hydrogen evolution, slow hydrogen gas formation and vigorous $\mathrm{H}_{2}$ bubbles evolution. For each potential, three different potential perturbation modes were also adopted: (a) a continuous electrodeposition at the chosen potential, (b) a unipolar square pulsed wave between the deposition potential and $0 \mathrm{~V}(\mathrm{SCE})$, (c) a unipolar trapezoidal pulsed wave between the same potential limits. Parameters of the pulsed perturbation methods are reported in Table 1 . In order to control NWs length, total deposition time was varied from 1 to $6 \mathrm{~h}$. An EG\&G (mod. 273A) potentiostat/sweep generator was employed for polarizing the working electrode; deposition current was monitored and acquired to a desk computer using an analogic interface, controlled through a home-made LABVIEW $7^{\mathrm{TM}}$ software.

Morphological characterization of samples was performed using a scanning electron microscope (ESEM XL 30), equipped with an X-ray energy dispersive spectrometer; prior to examination, samples were gold sputtered to avoid electrostatic charging effect. Sometimes template was dissolved by immersion in $1 \mathrm{M} \mathrm{NaOH}$ solution before SEM analysis. The crystallographic structure of NWs was investigated using a X-ray diffractometer, having a Philips generator (mod. PW 1130) and a PW goniometer (mod.1050); diffractograms were obtained in the $2 \theta$ range from 10 to 100 degrees with a step of 0.02 degrees and a measuring time of $0.5 \mathrm{~s}$ for step, using the $\mathrm{Cu} \mathrm{K} \alpha$ radiation $(\lambda=0.154 \mathrm{~nm})$.

Table 1

Parameters of pulsed waves employed for electrodeposition of $\mathrm{Cu}$ nanowires.

\begin{tabular}{|c|c|c|}
\hline Parameters & Square wave & Triangular wave \\
\hline $\begin{array}{l}t_{\text {off }} \\
\text { Scan } \\
E_{\text {dep }} \\
t_{\text {on }}\end{array}$ & $\begin{array}{l}10 \mathrm{~s} \\
\text { Step } \\
-0.3 ;-0.45 ;-0.6 \mathrm{~V}(\mathrm{SCE}) \\
1 \mathrm{~s}\end{array}$ & $\begin{array}{l}10 \mathrm{~s}^{-1} \\
1 \mathrm{~V} \mathrm{~s}^{-1} \\
-0.3 ;-0.45 ;-0.6 \mathrm{~V}(\mathrm{SCE}) \\
0.1 \mathrm{~s}\end{array}$ \\
\hline
\end{tabular}




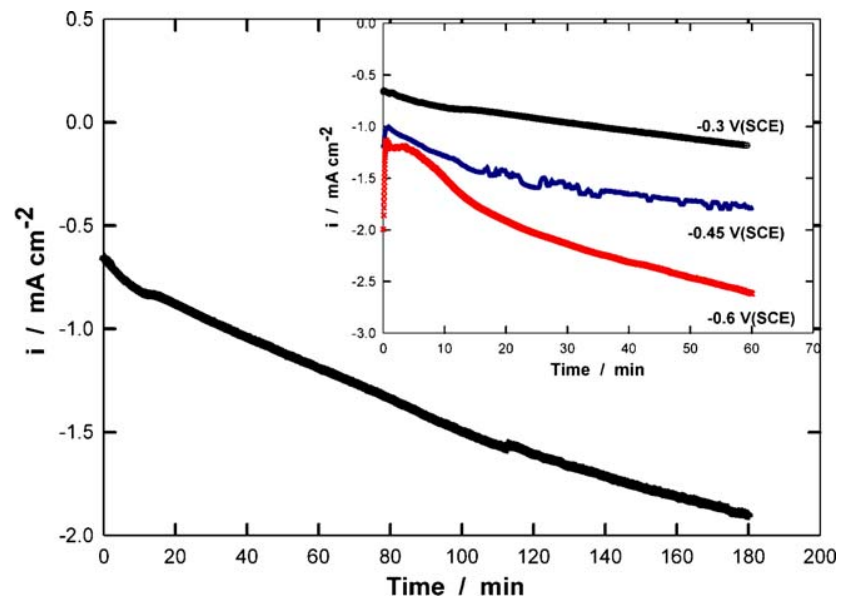

Fig. 1. Current density vs time plot during the growth of $\mathrm{Cu}$ nanowires at the constant potential of $-0.3 \mathrm{~V}(\mathrm{SCE})(3 \mathrm{~h})$. Inset: Current density vs time plots during the growth of $\mathrm{Cu}$ nanowires at different constant potentials $(1 \mathrm{~h})$.

\section{Results and discussion}

\subsection{Constant potential depositions}

Fig. 1 shows the current density vs time plot for a potentiostatic deposition performed at $-0.3 \mathrm{~V}(\mathrm{SCE})$. The time interval $(3 \mathrm{~h})$ was enough to fill completely the membrane pores (see below); besides, a continuous $\mathrm{Cu}$ overlayer was visible on the top surface of the template. The figure reveals a monotonous increase of the reduction current, starting from about $-0.7 \mathrm{~mA} \mathrm{~cm}^{-2}$. This behaviour can be justified with the decrease of electrical resistance within pores, owing to the progressive substitution of the electrolytic solution with the metallic wires. Hence, at this potential the process seems to occur under an ohmic control.

Similar features show the deposition curves at -0.45 and $-0.6 \mathrm{~V}(\mathrm{SCE})$, but with some interesting peculiarities for shorter times. In fact, an initial flash of negative current, more pronounced at the most negative potential, occurs in the first seconds soon after closing the circuit; as shown in the inset of Fig. 1 , where $1 \mathrm{~h}$ deposition experiments at all investigated potentials are reported for a better comparison. Such phenomenon must be ascribed to an initial flash of $\mathrm{H}_{2}$ evolution occurring on the sputtered gold film; this causes sudden gas bubbles formation into the alumina channels, with increase of solution resistance, followed by nucleation of metallic copper on gold. After the initial spike, the current gradually increases with the deposition time, like in the previous case, but with a higher slope with respect to the deposition performed at $-0.3 \mathrm{~V}$, due to the faster growth of metal NWs into membrane pores. At both potentials, more vigorous hydrogen bubbling was observed for the first few minutes, suggesting that kinetics of the concurrent process is much slower on $\mathrm{Cu}$ surface. It is worth to mention that a sudden increase of current density, expected as the complete filling of pores simultaneously occurs, it is not evident $[1,4]$ under continuous electrodeposition, because the growth rate of the NWs is not uniform inside each pore (see below). Some NWs grow more rapidly, therefore they reach the surface template before others.

Fig. $2 \mathrm{a}$ and $\mathrm{b}$ shows the cross-section of the template after, respectively, 1 and $3 \mathrm{~h}$ of deposition at $-0.3 \mathrm{~V}$. From Fig. 2a, it is evident that although the growth process involved all pores, NWs length is not uniform already after $1 \mathrm{~h}$ of deposition. At this potential, lengths ranging between 25 and $39 \mu \mathrm{m}$ were observed, whilst after $2 \mathrm{~h}$ of deposition the difference in length between different rods was smaller (34-39 $\mu \mathrm{m})$. This finding agrees with experimental observations on the potentiostatic electrodeposition of $\mathrm{Cu}$ and other nanostructures [4,26]; however, we mention that uniform lengths of $\mathrm{Cu}$ NWs were obtained in [27] by using very high overvoltages. Moreover, the comparison between average lengths measured after 1 and $2 \mathrm{~h}$ of deposition suggests a slower growth rate for longer times, likely caused by a progressive depletion of $\mathrm{Cu}^{2+}$ ions within membrane channels. This means that, already at this potential, the copper ions consumption is faster
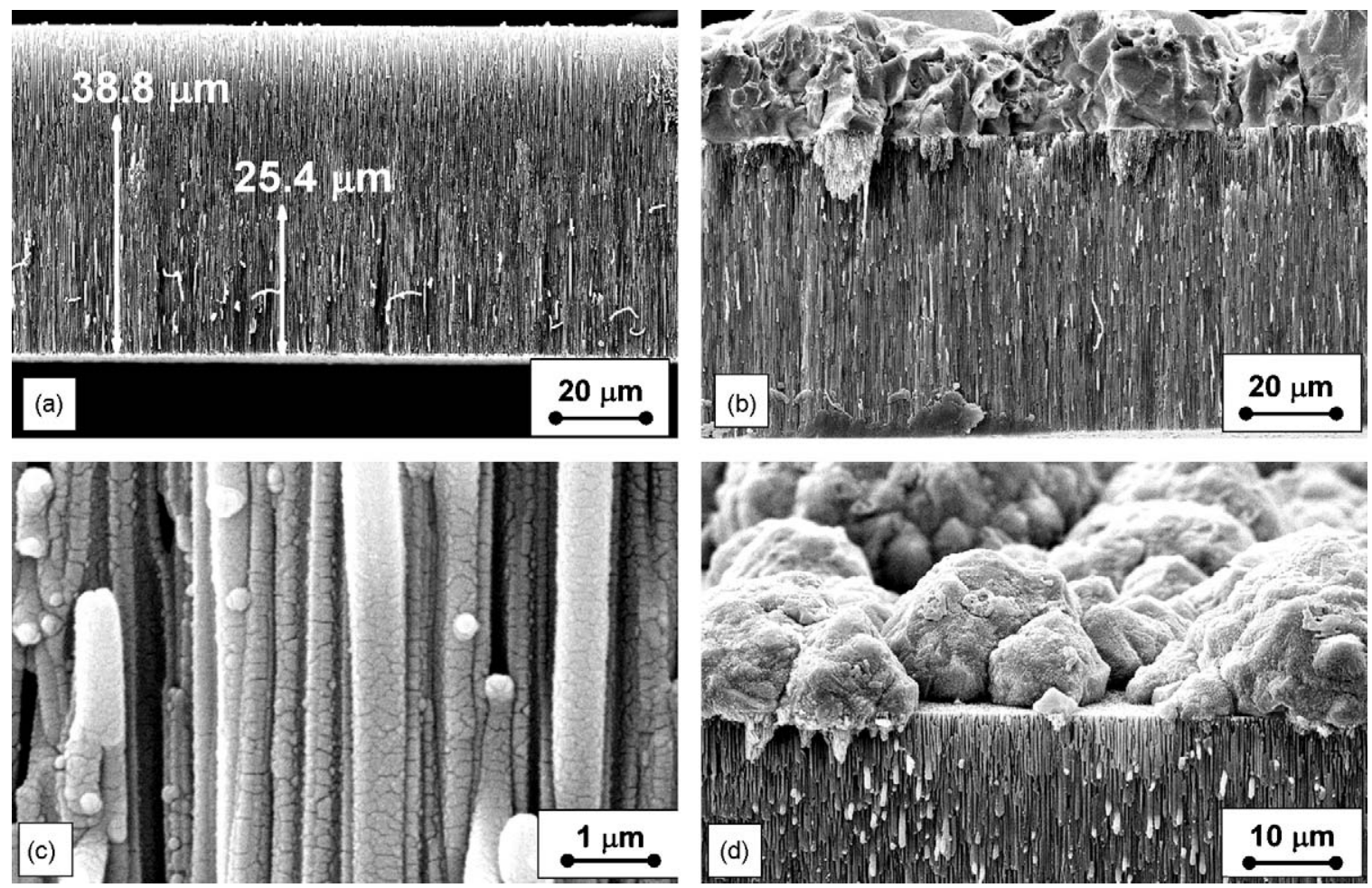

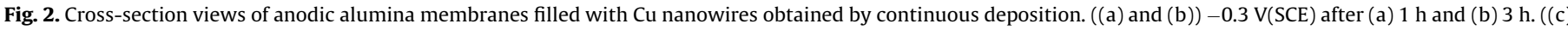
and (d)) $-0.6 \mathrm{~V}$ (SCE) after $1 \mathrm{~h}$ of electrodeposition in central part of the cross-section (c) and in proximity of the template surface (d). 
than their transport toward the electrode surface $[4,31,38]$. After $3 \mathrm{~h}$ of deposition at $-0.3 \mathrm{~V}$ most channels are completely filled and a continuous metal overlayer, about $20 \mu \mathrm{m}$ thick, is formed upon the external template surface exposed to the bath (Fig. 2b).

Similar results were obtained at more negative potentials, with the only difference of a faster growth of metallic NWs into the channels: complete pore filling and growth of an external metal layer were observed after $2 \mathrm{~h}$ of electrodeposition at $-0.45 \mathrm{~V}(\mathrm{SCE})$, and already after $1 \mathrm{~h}$ (see Fig. $2 \mathrm{c}$ and d) at $-0.6 \mathrm{~V}(\mathrm{SCE})$. This means that growth rate is higher than $55 \mu \mathrm{m} / \mathrm{h}$ at the most negative potential investigated. Anyway, we note that also in this case some pores were still partially filled (Fig. 2c), due to the non-uniform growth rate, and this explains the island-like morphology of the external deposit (Fig. 2d).

Composition and structure of deposited NWs were analyzed: the EDS spectra showed that NWs consist of pure copper metal. This was confirmed by X-ray diffractograms revealing a polycrystalline structure of the deposited metal (see Fig. 3) $[6,13,31,38]$. Identification of peaks, which are relative to the cubic structure of copper, was performed by comparison with the ICDD data-base, card no. 4-836 [40]. Moreover, comparison between samples grown for different times revealed different preferential growth, as evident from Fig. $5 \mathrm{a}$ and b, pertaining to NWs deposited at $-0.3 \mathrm{~V}$. Fig. $5 \mathrm{a}$ shows the XRD pattern of the deposit when NWs length is less than template thickness. It can be observed that copper deposit is polycrystalline, with preferential growth along the (1 111 ) and (2 200 ) planes. After $3 \mathrm{~h}$ of deposition, NWs reach the surface of the membrane and a copper layer $20 \mu \mathrm{m}$ thick is present. Therefore, in this case, a composite structure is formed, with a copper layer overlaying NWs filling the pores of the template. XRD patterns for surface deposit (Fig. 5b) shows that the most intense peak is relative to the (2 20 ) plane, indicating that copper compact layer preferentially grows along this plane. A confirmation of this different structure derives from the diffractogram (not shown here) performed on the back surface (that in contact with the gold substrate at pore bottom) of the sample of Fig. 3b, that is fully similar to that of Fig. 3a. Other differences of Fig. 3b with respect to Fig. $3 \mathrm{a}$ are the disappearance of the peaks relative to gold and the attenuation of the broad region around $2 \theta=25^{\circ}$, arising from the amorphous alumina template. Both originates from the coverage of the external membrane surface with a thick copper layer after $3 \mathrm{~h}$ deposition.

Diffractograms recorded for depositions performed at -0.45 and $-0.6 \mathrm{~V}(\mathrm{SCE})$ were quite similar, taking into account the higher growth rate of membrane pores: e.g., the X-ray pattern of a sample after $2 \mathrm{~h}$ deposition at $-0.45 \mathrm{~V}$ was coincident with that of Fig. 3b;

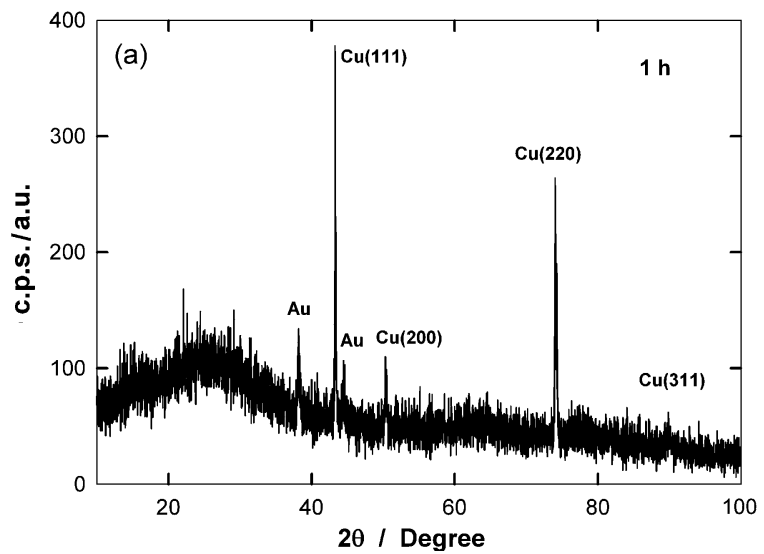

Table 2

Grain size, estimated through Eq. (1), of $\mathrm{Cu}$ nanowires grown by potentiostatic electrodeposition at different applied potentials and for different times.

\begin{tabular}{lll}
\hline Potential V(SCE) & Time $(\mathrm{h})$ & Grain size $(\mathrm{nm})$ \\
\hline-0.3 & 1 & 46.0 \\
-0.3 & 2 & 46.3 \\
-0.3 & 3 & 43.0 \\
-0.3 & 3 & 106 (layer) \\
-0.45 & 1 & 45.0 \\
-0.45 & 2 & 46.8 \\
-0.6 & 1 & 43.2 \\
\hline
\end{tabular}

in fact, also in this case, some pores were completely filled and a metallic layer was deposited onto the AAM external surface exposed to solution. However, at these more negative potentials, the main peak relative to the external layer was that pertaining to the ( $\left.\begin{array}{lll}1 & 1 & 1\end{array}\right)$ plane, at variance with the results obtained at $-0.3 \mathrm{~V}$. Contrary to the conclusions reached in [29], these results indicate that also at more negative potentials NWs consist of pure copper metal.

For all samples, the crystalline grain dimension $\left(d_{\mathrm{g}}\right)$ was estimated using the Scherrer equation [41]:

$d_{\mathrm{g}}=0.9 \lambda(B \cos \alpha)^{-1}(\mathrm{~nm})$

where $B$ is the half-height width of the main diffraction peak, $\lambda$ is the incident wavelength $(0.154 \mathrm{~nm}$, in our case) and $\alpha$ the diffraction angle. Results for the different samples are summarized in Table 2, where data relative to NWs and metallic overlayer were reported. From the data in Table 2, it appears evident that crystallites size of NWs is independent of deposition potential ( $45 \pm 2 \mathrm{~nm}$ ) and sensibly smaller than the size of grains grown on the external surface (about $105 \mathrm{~nm}$ ), the latter being also not appreciably influenced by potential. These results are in agreement with data reported in [31] and [38].

In conclusion, we may affirm that copper deposition under continuous potential produces a not uniform growth of cubic polycrystalline copper NWs with grain size of about $45 \mathrm{~nm}$ and without marked preferential growth along crystallographic planes. This structure is different from that of the compact metallic layer formed onto the template external surface, which shows a preferential orientation along the (2 20 ) or the (1 111 ) plane, depending on potential, and double crystallite size. More negative overvoltage results in the acceleration of the growth process, whilst the concurrent hydrogen evolution process seems to have little influence both on morphology and crystalline structure of the deposited metal.

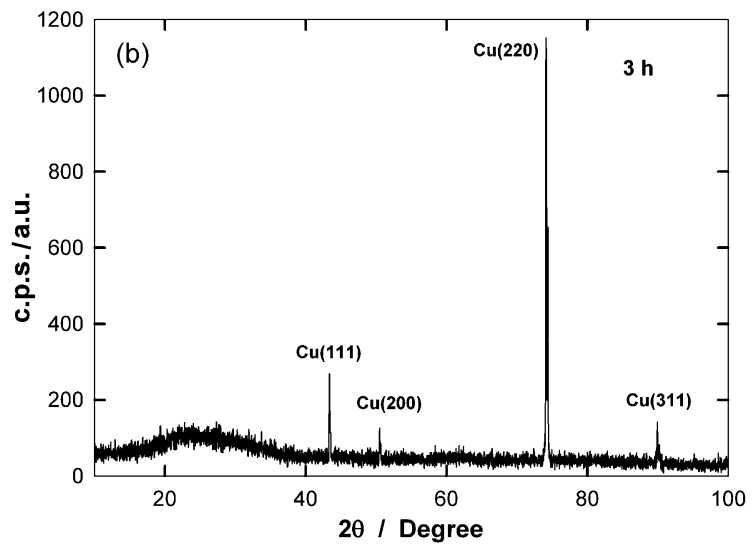

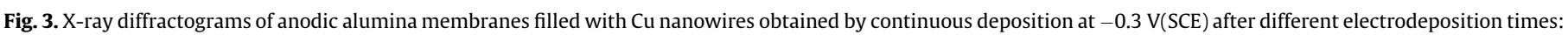
(a) $1 \mathrm{~h}$; (b) $3 \mathrm{~h}$. 


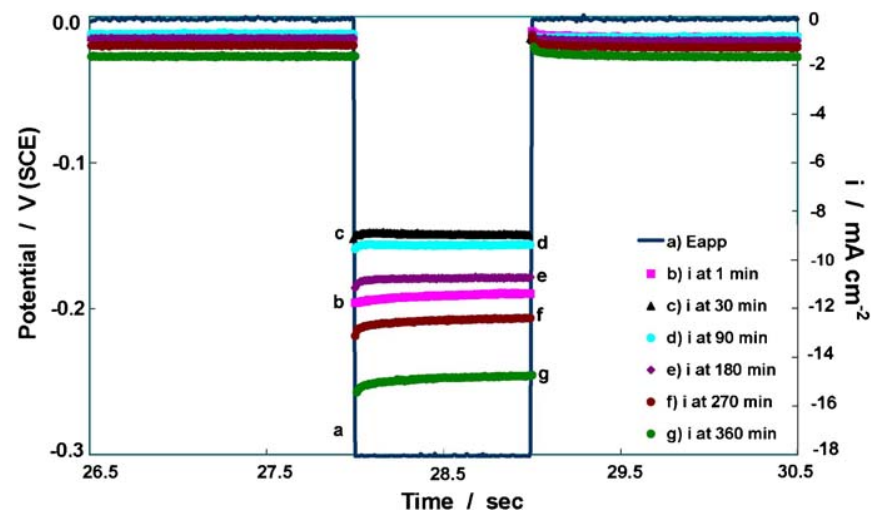

Fig. 4. Applied potential waveform (curve a) and current transients at different deposition times (curves $b-g$ ) recorded during a square pulsed electrodeposition of $\mathrm{Cu}$ nanowires performed between 0 and $-0.3 \mathrm{~V}(\mathrm{SCE})$.

\subsection{Depositions under pulsed potential}

Square pulsed deposition was performed according to the conditions reported in Table 1 . Usually, pulsed polarization is employed in order to replenish the double layer by inverting the polarity of the current. In this case, the potential pulse form was chosen in order to change only the value of current density, keeping polarity, because the fundamental objective was tuning deposition rate. By this way, a high deposition current was circulating during $t_{\mathrm{on}}$, whilst it was very low during $t_{\mathrm{off}}$. Also the cathodic pulse length was rather higher than usually done, even if there is no general rule indicating the best value of pulse length. The only significant parameter is the duty cycle, $t_{\mathrm{on}} /\left(t_{\mathrm{on}}+t_{\mathrm{off}}\right)$, in this case equal to $9.1 \%$, and therefore very far from a DC polarization [42].

Current transients after different deposition times are reported in Fig. 4 for a square pulsed deposition performed at $-0.3 \mathrm{~V}$ : apart from small spikes at the beginning of each transient, the current follows the potential perturbation, so that maximum $\left(i_{\max }\right)$ and minimum $\left(i_{\min }\right)$ current values in each step are very close. Interestingly, both values decrease during the first $50 \mathrm{~min}$ of deposition (from about $12-9 \mathrm{~mA} \mathrm{~cm}^{-2}$ ), and then increase again gradually (up to $15 \mathrm{~mA} \mathrm{~cm}^{-2}$ after $6 \mathrm{~h}$ of deposition (see also Fig. 5)). Very similar current transients were observed as square pulsed depositions was conducted between 0 and -0.45 or $-0.6 \mathrm{~V}$, confirming that deposition occurs always under ohmic control. Also for the other potentials, the change of current values with the

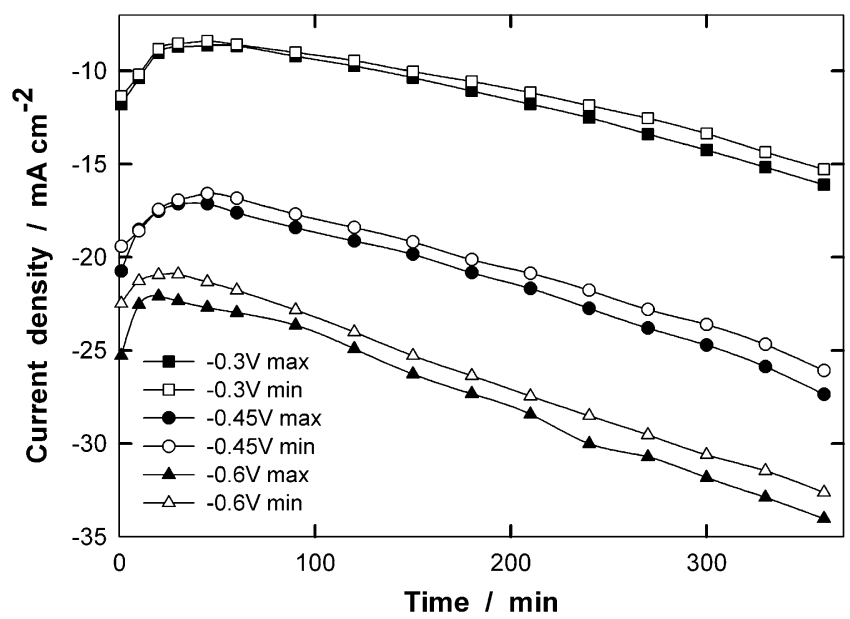

Fig. 5. Maximum and minimum current values measured at different total deposition times during the square pulsed transients of $\mathrm{Cu}$ nanowires electrodepositions.

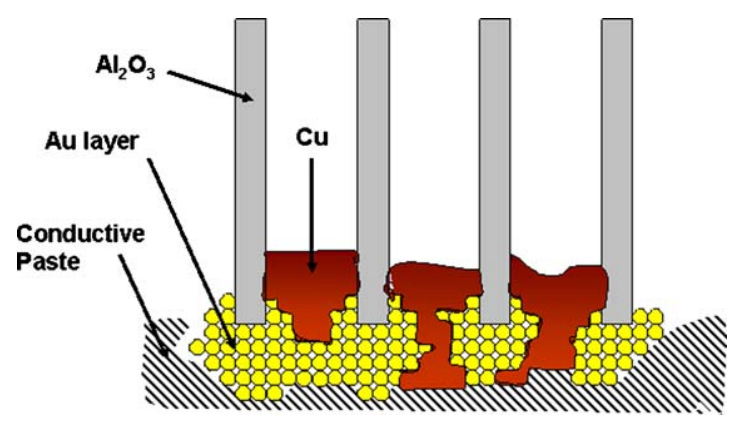

Fig. 6. Schematic representation of the Au layer covering pore bottom of the alumina template, and of the growing $\mathrm{Cu}$ deposit.

deposition time is non-monotonic, as shown in Fig. 5. This last figure evidences the differences arising from a different deposition potential; higher current values were measured at more negative potentials. Moreover, the minimum current is shifted toward shorter times, owing to the faster growth of NWs.

Considering that at $-0.3 \mathrm{~V}$ the hydrogen evolution cannot occur, the behaviour depicted in Fig. 5 seems related to the initial morphology of the electrode surface. In fact, SEM pictures (not shown here) reveal an extremely rough gold surface obtained by sputtering at pore bottom, which implies high real area for initial copper deposition. Whilst NWs grow, their top offers the new electrode surface for further deposition, and it is much smoother than the initial one. This means that during the first minutes of deposition the electrode surface area is diminishing, and this effect overcompensates the gradual increase in current due to pore filling, until NWs length is some tens of $\mu \mathrm{m}$ and gold is completely covered (see the scheme reported in Fig. 6). This occurs at shorter times for more negative potentials, where growth process is faster, and it explains the shift in current minimum of Fig. 5. From this point, only the effect of resistance lowering is present, and the cathodic current increases with time. Moreover, the larger differences between $i_{\max }$ and $i_{\min }$ at negative potentials should be ascribed to the presence of the $\mathrm{H}_{2}$ evolution reaction.

Similar results were observed performing a trapezoidal pulsed electrodeposition from the same bath (see Table 1). Also with this kind of perturbation, the current transients have the same shape of potential wave, as shown in the inset of Fig. 7. No evident current spikes are present. Again the current values decrease for short

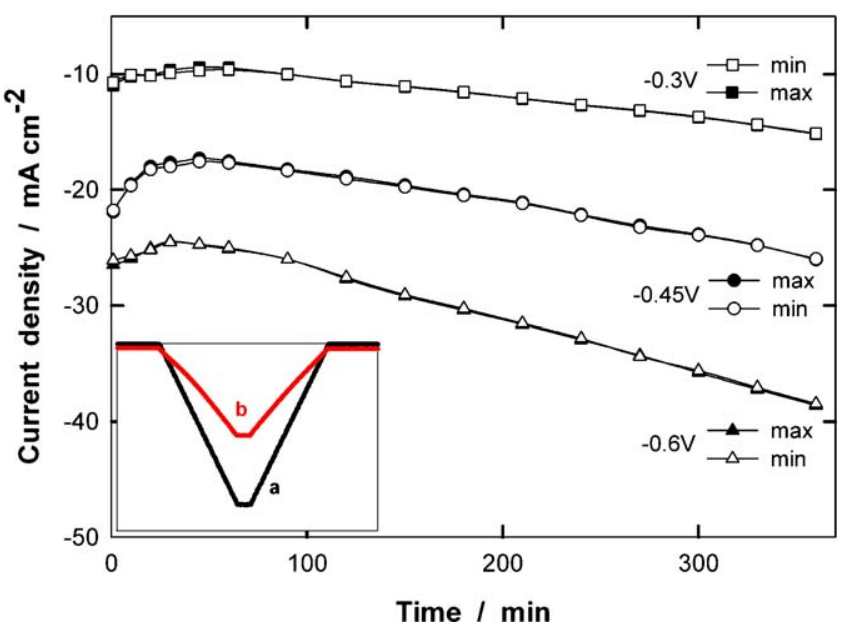

Fig. 7. Maximum and minimum current values measured at different total deposition times during the trapezoidal pulsed transients of $\mathrm{Cu}$ nanowires electrodepositions. Inset: Applied potential waveform (curve a) and typical current transients (curves b) recorded during a trapezoidal pulsed electrodeposition. 
Table 3

Grain size, estimated through Eq. (1), of $\mathrm{Cu}$ nanowires grown by pulsed electrodepositions for $1 \mathrm{~h}$.

\begin{tabular}{lll}
\hline Potential wave & Potential V(SCE) & Grain size $(\mathrm{nm})$ \\
\hline Square & -0.3 & 52.5 \\
Square & -0.45 & 45.7 \\
Square & -0.6 & 41.7 \\
Triangular & -0.3 & 40.9 \\
Triangular & -0.45 & 38.5 \\
Triangular & -0.6 & 34.3 \\
\hline
\end{tabular}

deposition times, and then they again gradually increase (Fig. 7), with a minimum value after about 50 min total deposition at $-0.3 \mathrm{~V}$, and shifting toward shorter times at more negative deposition potentials. Rationale for this behaviour is the same discussed above for the square pulsed deposition.

Analogous to the case of continuous deposition, for both unipolar pulsed depositions the membrane pores were filled uniformly with pure polycrystalline $\mathrm{Cu}$ NWs. X-ray diffraction patterns present the same peaks of those displayed in Fig. 3, and crystallites sizes, calculated by means of Eq. (1), are of the same order of magnitude (see Table 3). However, for pulsed depositions, a slight decrease of grain size is observed at more negative deposition potentials; moreover, the data in Table 3 evidence that grains are a little smaller when a trapezoidal potential pulse is applied, likely because the shortest permanence time at the deposition potential does not allow a further growth of the nucleated crystalline phase. For pulsed depositions, a continuous metallic layer deposited onto the membrane external surface was never observed, but only sporadic islands sometimes, because the lower growth rate (see below) prevented complete pore filling even after $6 \mathrm{~h}$ of deposition.

Shape of potential perturbation influences NWs growth rate and its uniformity between different membrane pores. Performing a square pulsed deposition at $-0.3 \mathrm{~V}(\mathrm{SCE})$, non-uniform lengths are observed between different channels since $1 \mathrm{~h}$ total deposition time, and this feature is enhanced for longer times. The average NWs length increases quite linearly with time, with an average growth rate of about $5.2 \mu \mathrm{m} / \mathrm{h}$ (see curve a of Fig. 8). However, the same kind of deposition carried out at more negative potentials results in much more uniform growth in different channels: in this case the initial growth rate is much higher (up to $15 \mu \mathrm{m} / \mathrm{h}$ during the first hour), but diminishing with time, as shown by curve b of

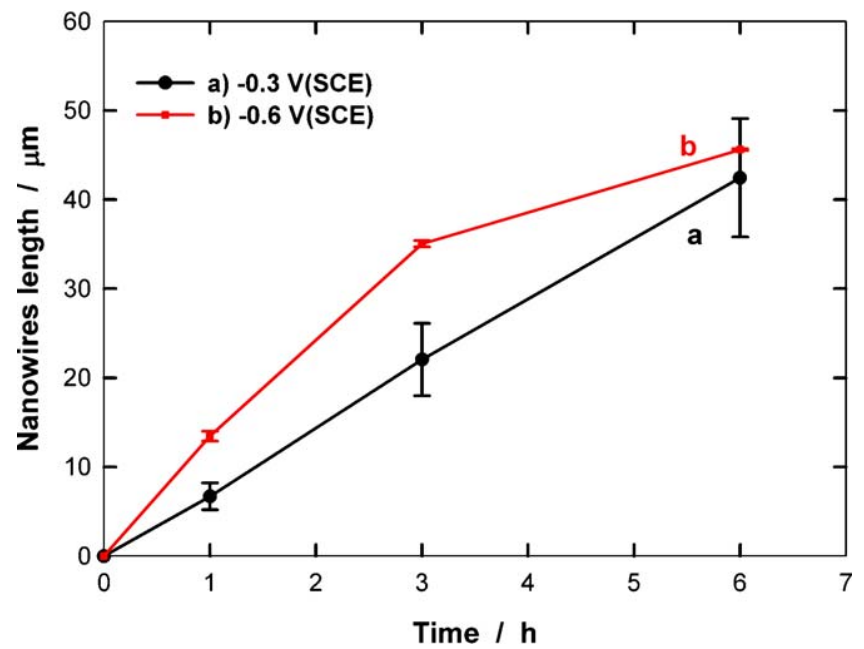

Fig. 8. Nanowires average length vs total electrodeposition time during square pulsed $\mathrm{Cu}$ electrodepositions at different potentials: (a) $-0.3 \mathrm{~V}(\mathrm{SCE})$; (b) $-0.6 \mathrm{~V}(\mathrm{SCE})$. Error bar represents nanowire length variation between different template channels.

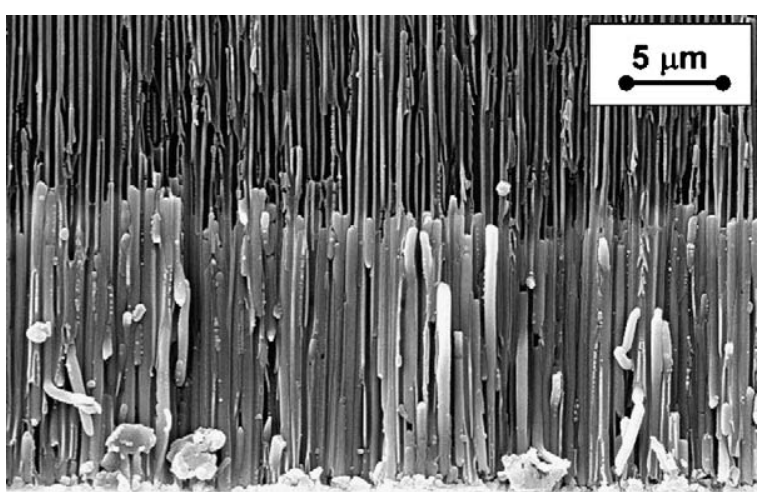

Fig. 9. Cross-section view of an anodic alumina membrane filled with $\mathrm{Cu}$ nanowires obtained by trapezoidal pulsed electrodeposition at $-0.6 \mathrm{~V}(\mathrm{SCE})$, after $3 \mathrm{~h}$ total deposition.

Fig. 8 for a square deposition between 0 and $-0.6 \mathrm{~V}$. The slow down of the growth process could be due to a depletion of $\mathrm{Cu}^{2+}$ ions into the channels, faster in those pores where higher initial rates occur; this should explain more uniform lengths observed at longer deposition times. Anyway, an effect of the hydrogen evolution reaction cannot be ruled out. We note that growth rates are far below those observed under continuous deposition at the corresponding potentials, as expected owing to the large time intervals elapsed at $0 \mathrm{~V}(\mathrm{SCE})$, where copper deposition occur with a very low current density.

Even slower growth is observed during pulsed trapezoidal depositions at the same potentials. Here the effect of deposition potential upon length uniformity is different with respect to the previous case. At $-0.3 \mathrm{~V}$, the growth of NWs in different membranes pores is quite uniform for the first $3 \mathrm{~h}$, with an initial rate close to $5.5 \mu \mathrm{m} / \mathrm{h}$, whilst for longer deposition times it becomes less uniform, giving lengths ranging between 32 and $36 \mu \mathrm{m}$ after $6 \mathrm{~h}$, and thus the channels are never completely filled. The same holds at more negative deposition potentials, as revealed by the SEM picture of Fig. 9: at this potential, the growth almost stops between 1 and $3 \mathrm{~h}$ and then increases again, but with different rates in different channels, so that after $6 \mathrm{~h}$ lengths ranging between 25 and $35 \mu \mathrm{m}$ are observed.

Whilst it is easy to conclude that with this perturbation potential mode it is desirable to work at $-0.3 \mathrm{~V}(\mathrm{SCE})$ in order to obtain more uniform lengths, and that square pulse deposition at -0.45 or $-0.6 \mathrm{~V}$ gives higher and more uniform lengths of copper NWs, a rationale for these findings is not simple. It is obvious that the higher growth rates observed under square pulsed potential perturbation with respect to the trapezoidal one, must be ascribed to the longer net time elapsed at the lowest (deposition) potential in the former case; however, the results about the uniformity of NWs length seem contradictory, because choosing a more negative deposition potential seems beneficial for the square pulsed deposition and detrimental when a trapezoidal potential perturbation is imposed. Seemingly, in the latter case a heavier interference of the concurrent hydrogen evolution process occurs, causing random bubbles accumulation into some pores that slows down further metal deposition, whilst under a square perturbation the produced hydrogen is more rapidly consumed during the highpotential step. However, this aspect needs more investigations in order to be clarified.

\subsection{Self-standing free nanowires}

Anodic alumina is not only a suitable template for metallic NWs fabrication, but it constitutes also an ideal environment for their use into small devices. In fact the perfect insulating behaviour of 

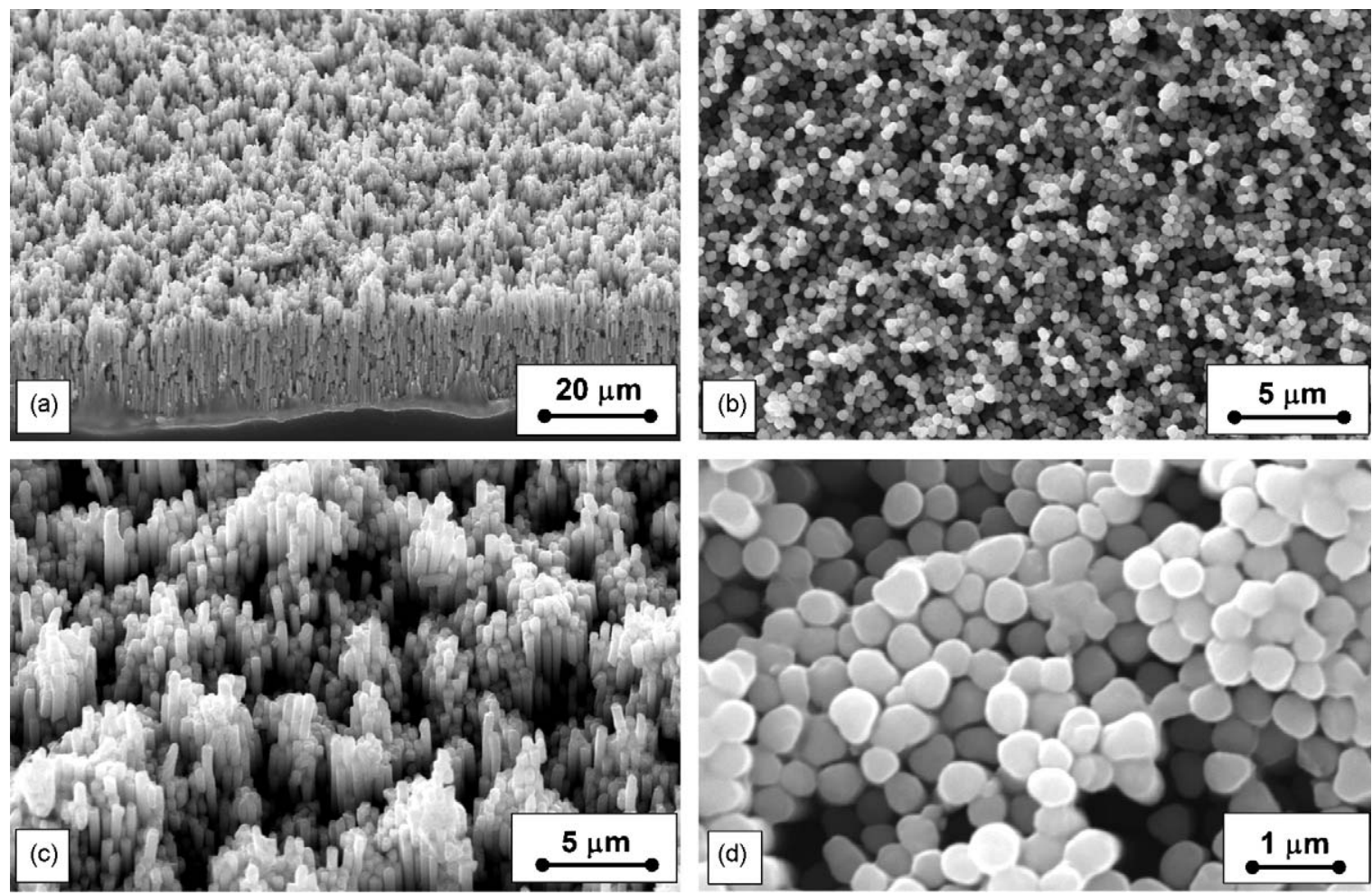

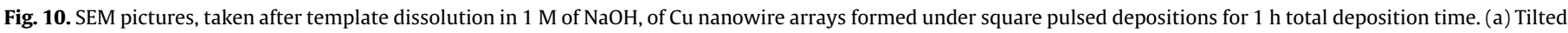

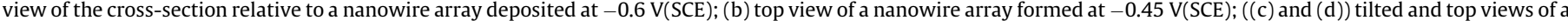
nanowire array formed at $-0.3 \mathrm{~V}(\mathrm{SCE})$.

aluminium oxide ensures the unidimensional current flow through the array of metallic NWs closely spaced, once electrical contacts are placed onto the external membrane surfaces. Despite this fact, it is important to check the mechanical stability of the metallic NWs alone, as well as the possibility to retain their geometrical order (in particular, the parallelism between different wires) independent of the template support. Moreover, it is important to assess the adherence of copper NWs to the gold layer constituting the initial electrode surface. In order to check this issue, for a certain number of samples, we performed a complete dissolution of the alumina membrane after copper nanostructures fabrication. This was achieved by immersion of the template in $1 \mathrm{M} \mathrm{NaOH}$ aqueous solution at room temperature for a suitable time. The latter was of the order of $2 \mathrm{~h}$ for membrane total dissolution, but it was varied when partial dissolution was desired. Afterwards, the samples were examined by scanning electron microscopy.

Results of such an investigation are reported in Fig. 10, showing SEM pictures of the $\mathrm{Cu}$ nanowire arrays formed under square pulsed deposition at different potentials and for $1 \mathrm{~h}$ total deposition. Fig. 10a, which is relative to an array deposited at $-0.6 \mathrm{~V}$ (SCE) evidences that template dissolution does not alter the alignment between NWs, which are firmly hammered in the thin gold layer visible at the bottom [13]. Moreover, an acceptably uniform length is visible. The enormous surface density of NWs is perceptible from the top view of Fig. 10b, relative to an array formed at $-0.45 \mathrm{~V}$, for the same time and deposition method. Since the $\mathrm{Cu}$ deposition occurred in each pore, such a density is the same of pore population of the alumina membrane, i.e., of the order of $10^{13}$ wire $\mathrm{m}^{-2}$. More details about NWs geometry are discernible from the enlarged views of Fig. 10c and d, where the cylindrical shape of NWs (diameter: $210 \mathrm{~nm}$ ) is distinguishable. These last pictures are relative to an array formed at $-0.3 \mathrm{~V}$ (SCE) for $1 \mathrm{~h}$ under square pulsed deposition, resulting in non-uniform lengths (see above), as evidenced in Fig. 10c. Analogous results were observed for the other potential perturbations after template dissolution. In conclusion, copper NW arrays fabricated by electrodeposition from the selected bath retain their parallel order even after membrane dissolution.

\section{Conclusions}

A systematic investigation has been carried out in order to study the influence of the electrochemical parameters on growth rate, length and crystalline structure of metallic copper NWs electrodeposited into the pores of alumina templates from a $\mathrm{Cu}^{2+}$ ion-containing bath at $\mathrm{pH} 3$. For this purpose, different deposition potentials and voltage perturbation modes were employed. The potential was varied in order to carry out the growth in the absence of hydrogen evolution (at $-0.3 \mathrm{~V}(\mathrm{SCE})$ ), as well as in the presence of such a concomitant reaction, both with small and high overvoltage (at -0.45 and $-0.6 \mathrm{~V}$, respectively). Depositions under either continuous or unipolar pulsed potential were carried out. In the latter case, either a square or a trapezoidal wave form were applied, both between $0 \mathrm{~V}(\mathrm{SCE})$ and the deposition potential.

Regardless of the deposition potential and perturbation mode, the electrodeposition process resulted always in the formation of pure polycrystalline copper NWs, with preferential orientation along the ( $\left.\begin{array}{lll}1 & 1 & 1\end{array}\right)$ or $\left(\begin{array}{lll}2 & 2 & 0\end{array}\right)$ plane. Crystalline grain size was about $45 \mathrm{~nm}$, independent of the applied potential, for continuous electrodeposition. With this method, the length of NWs was not uniform, and complete filling of several pores was reached after reasonably short deposition times ( $3 \mathrm{~h}$ at $-0.3 \mathrm{~V}, 1 \mathrm{~h}$ at $-0.6 \mathrm{~V}$ ). At this point, NWs having an aspect ratio of about 260 were obtained, but a metal layer began to form onto the membrane external surface exposed to the solution, having a polycrystalline structure with a larger grain size (about $100 \mathrm{~nm}$ ).

Remarkable influence was exerted by deposition method and potential on both the NW growth rate and length uniformity. In particular, quite uniform length of NWs grown in different pores was achieved performing a square pulsed deposition at more 
negative potentials, even if growth rate was sensibly smaller in comparison to the formation at constant potential, and further decreasing with the total deposition time. This implies that complete pore filling was achieved after about $7 \mathrm{~h}$ of deposition. On the contrary, a trapezoidal pulsed deposition was detrimental for both the growth rate (even slower) and non-uniform length of NWs.

An interesting result is that in all cases the metallic NWs are selfstanding mechanically, i.e., they retain their vertical parallel geometry even after total membrane dissolution, stemming out from the basal gold layer. Thus, the template structure is not essential for their use in a device, even if the ideally insulating properties of alumina could help in obtaining the desired performances.

\section{Acknowledgements}

This work was supported by Università di Palermo. The authors would like to thank Dr. Giusy Marino for performing some experiments.

\section{References}

[1] G. Cao, Nanostructures \& Nanomaterials: Synthesis Properties \& Applications, Imperial College Press, Weinheim, 2004.

[2] Ali Eftekhari (Ed.), Nanostructured Materials in Electrochemistry, Wiley, Weinheim, 2008.

[3] G. Riveros, H. Gómez, R. Schrebler, R.E. Marotti, E.A. Dalchiele, Electrochem, Solid State Lett. 11 (2008) K19.

[4] M. Motoyama, Y. Fukunaka, T. Sakka, Y.H. Ogata, Electrochim. Acta 53 (2007) 205.

[5] D. Dobrev, J. Vetter, N. Angert, R. Neumann, Appl. Phys. A 69 (1999) 233.

[6] S. Thongmee, H.L. Pang, J. Ding, J.Y. Lin, J. Magn. Magn. Mater. (2009), doi:10.1016/ j.jmmm.2009.03.074.

[7] W. Liang, M. Zhou, F. Ke, Nano Lett. 5 (2005) 2039.

[8] Y.P. Liang, Q.Z. Shi, Z.S. Wu, Y.Y. Wang, S.L. Gao, Chinese J. Chem, 23 (2005) 261

[9] G.A. Gelves, U. Sundararaj, J.A. Haber, Macromol. Rapid Comm. 26 (2005) 1677.

[10] X. Chen, H. Duan, Z. Zhou, J. Liang, J. Gnanaraj, Nanotechnology 19 (2008) 365306.

[11] P.L. Taberna, S. Mitra, P. Poizot, P. Simon, J.M. Tarascon, Nat. Mater. 5 (2006) 567.

[12] X. Su, L. Zhang, Q. Li, D. Liang, Chin. Opt. Lett. 6 (2008) 297.

[13] H. Cao, L. Wang, Y. Qiu, L. Zhang, Nanotechnology 17 (2006) 1736.
[14] Q. Huang, C.M. Lilley, M. Bode, R. Divan, 8th IEEE Conference on Nanotechnology, IEEE-NANO, (2008), p. 549, art. no. 4617145.

[15] P.C. Andricacos, C. Uzoh, J.O. Dukovic, J. Horkans, H. Deligianni, IBM J. Res. Dev. 42 (1998) 567.

[16] C. Fang, E. Foca, S. Xu, J. Carstensen, H. Foll, J. Electrochem. Soc. 154 (2007) D45.

[17] T. Chowdhury, D.P. Casey, J.F. Rohan, Electrochem. Comm. (2009), doi:10.1016/ j.elecom.2009.04.003.

[18] R. Inguanta, S. Piazza, C. Sunseri, Electrochem. Comm. 10 (2008) 506.

[19] R. Inguanta, S. Piazza, C. Sunseri, Italian Pat. (2007) VI-2007-A000275.

[20] L. Gonzalez-Rovira, J.M. Sanchez-Amaya, M. Lopez-Haro, A.B. Hungria, Z. Boukha, S. Bernal, F.J. Botana, Nanotechnology 19 (2008) 495305.

[21] L. Gonzalez-Rovira, J.M. Sanchez-Amaya, M. Lopez-Haro, E. del Rio, A.B. Hungria, P. Midgley, J.J. Calvino, S. Bernal, F.J. Botana, Nano Lett. 9 (2009) 1395.

[22] K.J. Ziegler, P.A. Harrington, K.M. Ryan, T. Crowley, J.D. Holmes, M.A. Morris, J. Phys.: Condens. Matter 15 (2003) 8303.

[23] Y. Chang, M.L. Lye, H.C. Zeng, Langmuir 21 (2005) 3746.

[24] Q. Huang, C.M. Lilley, M. Bode, R. Divan, J. Appl. Phys. 104 (2008) 023709.

[25] K. Nielsh, F. Muller, A.P. Li, U. Gösele, Adv. Mater. 12 (2002) 582.

[26] R. Inguanta, S. Piazza, C. Sunseri, Electrochim. Acta 53 (2008) 5766

[27] N. Gerein, J. Haber, J. Phys. Chem. B 109 (2005) 17372.

[28] X.L. Liu, H.P. He, J.H. Zhou, W.J. Dang, Rare Metal Mater. Eng. 36 (2007) 2228.

[29] T. Gao, G. Meng, Y. Wang, S. Sun, L. Zhang, J. Phys.: Condens. Matter. 14 (2002) 355

[30] F. Maurer, J. Brötz, S. Karim, M.E. Toimil Molares, C. Trautmann, H. Fuess, Nanotechnology 18 (2007) 135709.

[31] M.E. Toimil Molares, V. Buschmann, D. Dobrev, R. Neumann, R. Scholz, I.U. Schuchert, J. Vetter, Adv, Mater. 13 (2001) 62

[32] R. Inguanta, M. Butera, C. Sunseri, S. Piazza, Appl. Surf. Sci. 253 (2007) 5447.

[33] R. Inguanta, S. Piazza, C. Sunseri, Electrochim. Acta 53 (2008) 6504.

[34] R. Inguanta, C. Sunseri, S. Piazza, Electrochem. Solid-State Lett. 10 (2007) K63.

[35] R. Inguanta, S. Piazza, C. Sunseri, Nanotechnology 18 (2007) 485605.

[36] R. Inguanta, S. Piazza, C. Sunseri, J. Electrochem. Soc. 155 (2008) K205.

[37] G. Ferrara, R. Inguanta, S. Piazza, C. Sunseri, Electrochem. Solid-State Lett. 12 (2009) K17.

[38] M.E. Toimil Molares, J. Brötz, V. Buschmann, D. Dobrev, R. Neumann, R. Scholz, I.U. Schuchert, C. Trautmann, J. Vetter, Nucl. Instrum. Methods Phys. Res. B 185 (2001) 192.

[39] C. Schönenberger, B.M.I. van der Zande, L.G.J. Fokkink, M. Henny, C. Schmid, M. Krüger, A. Bacttold, R. Huber, H. Birk, U. Staufer, J. Phys. Chem. B 101 (1997) 5497.

[40] Joint Committee Powder Diffraction Standards, Power Diffraction file, International Centre for Diffraction Data, Card No. 4-836, Pennsylvania, USA, 2007.

[41] A.R. West, Solid State Chemistry and its Applications, Wiley, Chichester, 1985 (chapter 3).

[42] N.V. Mandich, Metal Finishing 98 (2000) 375. 